\title{
The Trojan Horse Strategies of Parasites
}

\author{
Aline Scovino ${ }^{1}$, Aryanne Trigueiros ${ }^{1}$ and Alexandre Morrot ${ }^{1,2 *}$ \\ ${ }^{1}$ Laboratório de Imunoparasitologia, Instituto Oswaldo Cruz, Fiocruz, Rio de Janeiro, Brazil \\ ${ }^{2}$ Centro de Pesquisas em Tuberculose, Instituto de Microbiologia, Faculdade de Medicina, Universidade Federal do Rio de Janeiro, Rio de Janeiro, Brazil
}

*Corresponding author: Alexandre Morrot, Laboratório de Imunoparasitologia, Instituto Oswaldo Cruz, Fiocruz, Rio de Janeiro, Brazil; E-mail: alexandre.morrot@ioc. fiocruz.br, alexandre.morrot@medicina.ufrj.br

Received: May 14, 2021; Accepted: May 24, 2021; Published: May 29, 2021

The Trojan Horse is a legendary figure of a wooden horse used by the Greeks during the Trojan War to invade and destroy the Trojan city. Inside this seemingly harmless horse, supposedly sent as a sign of truce, were Greek warriors who at dusk, when the Trojan defenses were unarmed, took advantage to attack the city. This legendary figure can be used as an excellent analogy for the mechanisms some pathogens have adopted to invade the host and evade detection by the immune system. The 'Trojan Horse Theory' in immunology describes the ability of some microorganisms, using cells of the immune system itself as vectors, to escape the immune response.

The cells commonly used by these pathogens are phagocytes, such as neutrophils and macrophages, which are the first cells to reach the site of infection. These cells have microbicidal mechanisms that are able to eliminate the pathogen and aid in the control of infection. These mechanisms depend on the production of cytokines and chemokines, as well as the production of reactive oxygen and interferon species. However some pathogens are able to circumvent or inhibit some of these mechanisms thus allowing their survival, as well as enabling their dissemination to target sites, where they will multiply protected from the action of the immune system [1].

The neutrophil is the first cell that migrates to infected tissue after inoculation of the promastigote form of the protozoan parasites of the genus Leishmania. Leishmania is capable of inhibiting neutrophil proinflammatory cytokine production, such as TNF- $\alpha$, increasing the production of anti-inflammatory cytokines, such as TGF- $\beta$, as well as preventing neutrophil microbicidal activity by negatively regulating IFN- $\gamma$. In addition, the parasite is capable of retarding neutrophil apoptosis, which would naturally go into apoptosis 6-10 hours after activation, to up to two days. Leishmania achieves this by interfering with the caspase pathway, preventing the processing of pre-caspase into caspase $3[2,3]$.

The infected and apoptotic neutrophil secretes high levels of the chemokine MIP-1b, which attracts macrophages to the infection site. The moment the infected neutrophil becomes apoptotic and releases MIP-1b coincides with the peak migration of macrophages into infected tissue, so in situ macrophages encounter apoptotic neutrophils containing intracellular parasites rather than free Leishmania promastigotes. Since apoptotic cell phagocytosis is an anti-inflammatory signal, macrophage microbicidal functions are not activated, and the parasite survives [3].
The Trojan Horse Theory can also used to explain how some microorganisms can overcome the blood-brain barrier to reach the brain. The blood-brain barrier is composed of endothelial cells lining the vascular and cerebral system and plays an essential role in the maintenance of hemostasis of neurons and glial cells, and blocking access of endogenous or exogenous toxic substances, including microorganisms [4]. However, some pathogens are able to cross this barrier. The first step is the infection of a phagocyte in the periphery. Once internalized, the pathogen can actively manipulate the phagocyte to promote brain migration; alternatively, it can suppress phagocyte activation and consequent sequestration in the source tissue, allowing the infected cell to circulate normally throughout the body. When an infected phagocyte reaches the brain, it adheres to the luminal side of the brain capillaries (with or without activation of BMECs) and crosses the blood-brain barrier between or through endothelial cells. Upon entry into the brain, the pathogen can exit its Trojan horse to infect other neural structures [5]. This model has been elucidated in more detail for HIV6 and other viruses, but other studies indicate similar strategies are utilized by some bacteria, fungi and protozoa, such as Listeria monocytogenes [6-10], Cryptococcus neoformans [11] and Plasmodium spp [12].

The dendritic cell (DC) can also act as a Trojan horse in some infections. During HIV infection, DCs perform two contradictory functions. On the one hand they are essential for building an efficient response against the virus, and are even the target of several studies for the development of HIV vaccines, whilst on the other hand it carries the virus directly to its target cell, the $\mathrm{CD} 4^{+} \mathrm{T}$ lymphocyte [13]. The CD4 molecule is the HIV-1 receptor, its binding to this receptor and the CCR5 or CXCR4 co-receptors allows the virus to enter the cell and follow its conventional viral cycle, including retrotranscription of its genetic material and integration into the genome. Productive CD infection is a very rare event, less frequent than $\mathrm{CD}^{+} \mathrm{T}$ lymphocyte infection. The type-C lectin receptor, DC-SIGN, which is highly expressed in local DCs.

\section{References}

1. Medzhitov R (2007) Recognition of microorganisms and activation of the immune response. NATURE 449: 18. [crossref]

2. van Zandbergen G, Klinger M, Muller A, Dannenberg S, Gebert A, (2004) b. Cutting edge: neutrophil granulocyte serves as a vector for Leishmania entry into macrophages. J Immunol 173: 6521-6525. [crossref]

3. Laskay T, Zandbergen G, Solbach W (2007) Neutrophil granulocytes as host cells and transport vehicles for intracellular pathogens: Apoptosis as infection-promoting factor. Immunobiology 213: 183-191. [crossref] 
4. Daneman R, Prat A (2015) The blood-brain barrier. Cold Spring Harb Perspect Biol 7: a020412. [crossref]

5. Santiago-Tirado FH, Doering TL (2017) False friends: Phagocytes as Trojan horses in microbial braininfections. PLOS Pathogens 13(12). [crossref]

6. Kim WK, Corey S, Alvarez X, Williams K (2003) Monocyte/macrophage traffic in HIV and SIVencephalitis. J Leukoc Biol 74: 650-656. [crossref]

7. Prats N, Briones V, Blanco MM, Altimira J, Ramos JA, et al. (1992) Choroiditis and meningitis in experimental murine infection with Listeria monocytogenes. Eur J Clin Microbiol Infect Dis 11: 744-747. [crossref]

8. Drevets DA, Bronze MS (2008) Listeria monocytogenes: epidemiology, human disease, and mechanisms of brain invasion. FEMS Immunol Med Microbiol 53: 151165. [crossref]
9. Drevets DA, Jelinek TA, Freitag NE (2001) Listeria monocytogenes-infected phagocytes can initiate central nervous system infection in mice. Infect Immun 69: 1344-1350. [crossref]

10. Join-Lambert OF, Ezine S, Le Monnier A, Jaubert F, Okabe M, et al. (2005) Listeria monocyto-genes-infected bone marrow myeloid cells promote bacterial invasion of the central nervous system. Cell Microbiol 7: 167-180. [crossref]

11. Srikanta D, Santiago-Tirado FH, Doering TL (2014) Cryptococcus neoformans: historical curiosity to modern pathogen. Yeast 31: 47-60. [crossref]

12. Wykes MN, Horne-Debets J (2012) Dendritic cells: The Trojan horse of malaria? International Journal for Parasitology 42: 583-587. [crossref]

13. Martín-Moreno A, Muñoz-Fernández MA (2019) Dendritic Cells, the Double Agent in the War Against HIV-1. Front Immunol 10: 2485. [crossref]

\section{Citation:}

Scovino A, Trigueiros A, Morrot A (2021) The Trojan Horse Strategies of Parasites. Trends in Vaccines and Immunology Volume 1(2): 1-2. 